\title{
Depression, Anxiety and Stress Among Indians in Times of Covid-19 Lockdown
}

\author{
Usama Rehman ${ }^{1} \cdot$ Mohammad G. Shahnawaz $^{2} \cdot$ Neda H. Khan ${ }^{2} \cdot$ Korsi D. Kharshiing ${ }^{2} \cdot$ Masrat Khursheed $^{2}$. \\ Kaveri Gupta ${ }^{2} \cdot$ Drishti Kashyap $^{2} \cdot$ Ritika Uniyal $^{2}$
}

Received: 5 May 2020 / Accepted: 19 June 2020 / Published online: 23 June 2020

○) Springer Science+Business Media, LLC, part of Springer Nature 2020

\begin{abstract}
Covid-19 has caused significant distress around the globe. Apart from the evident physical symptoms in infected cases, it has caused serious damage to public mental health. India, like other countries, implemented a nationwide lockdown to contain and curb the transmission of the virus. The current research is an attempt to explore psychological distress among people residing in India during the lockdown. Four hundred and three participants were asked to complete a questionnaire with questions around symptoms of depression, anxiety, stress, and family affluence. The results indicated that people who do not have enough supplies to sustain the lockdown were most affected, and family affluence was found to be negatively correlated with stress, anxiety, and depression. Among different professions, students and healthcare professionals were found to experience stress, anxiety, and depression more than others. Despite the current situation, stress, anxiety, and depression were found to be in normal ranges for mental health professionals highlighting their capabilities to remain normal in times of distress. Policymakers and other authorities may take the assistance of mental health professionals to help overcome psychological issues related to Covid-19.
\end{abstract}

Keywords Covid-19 $\cdot$ Coronavirus $\cdot$ Depression $\cdot$ Anxiety $\cdot$ Stress $\cdot$ Depression $\cdot$ India $\cdot$ Students $\cdot$ Mental health professionals

\section{Introduction}

Covid-19, commonly known as the novel Coronavirus is believed to have originated from a wet market in Wuhan, China, and has spread all over the world, resulting in a large number of hospitalizations and deaths (Wang et al. 2020). As of April 18, there were approximately 23,00,000 cases reported from across the globe (Worldometers 2020). Presently, with no medicine or vaccine available for Covid-19 (Sanders et al. 2020) the situation has turned worrisome. More than a third of the world's population has been put under lockdown with restricted movements to contain the widespread of the virus (Kaplan et al. 2020). People have been strictly advised to maintain social distance, wear

Usama Rehman

Usama.ktw@gmail.com

1 Department of Psychology, Aligarh Muslim University, Aligarh, India

2 Department of Psychology, Jamia Millia Islamia, New Delhi, India a mask, and sanitize their hands frequently (Cheng et al. 2020). India is no different from rest of the world, when it comes to the lockdown (Sahu et al. 2020). For Indians, challenges in the medical sector, further deepens the worries (Chetterje 2020) that heighten psychological distress.

In times of an epidemic, people tend to experience fear of getting infected with the virus/disease resulting in anxiety, stress, and depression, etc. (Hall et al. 2008). Stress can be explained as a feeling of emotional and physical tension which arises from any event that threatens our homeostasis (Selye 1956). On the other hand, the fear of the unknown is termed as anxiety, that is the body's natural response to stress (Holland 2018). Depression is viewed as a state of disinterest in daily activities. It is surmised that people facing a pandemic with no vaccination would result in fear of the unknown (in this case, the coronavirus) making them anxious, stressed and depressed. Keeping in mind the concerns regarding psychological distress raised around the globe, Xiang et al. (2020) have argued for a timely action on mental health during the Covid-19 pandemic. Furthermore, the World Heath Organization (WHO 2020) has also 
issued public interest guidelines to address psychological issues that may arise. What is alarming is the heightened fear related to the coronavirus culminating in people committing suicides (Goyal et al. 2020; Mamun and Griffiths 2020). A study by Wang et al. (2020) reported severe psychological distress (anxiety, stress, and depression) during Covid-19 among Chinese nationals. Similarly, another research on Chinese nationals found psychological distress such as stress, anxiety, and depression quite common and hence, alarming (Qiu et al. 2020). Evidently, people's mental health was badly affected during pandemics such as SARS. For example, Leung et al. (2003) found that his respondents reported experiencing anxiety during SARS. Moreover, stress, depression, and anxiety were also found to be common among people during SARS (McAlonan et al. 2007), however, these were significantly higher for the high-risk population such as health workers. In yet another research, Hawryluck et al. (2004) found that people who were quarantined during SARS reported a high level of psychological distress. Clearly, being social is a human tendency that facilitates social interaction, and thus, when our movements are curtailed, psychological distress results (Usher et al. 2020). Van Bortel et al. (2016), and Kumar and Nayar (2020) have suggested that issues of mental health should be considered and also addressed as anxiety, stress, fear, trauma, helplessness and other psychological issues are experienced during a pandemic.

It appears that in India, the present lockdown affects people differently with regards to their sex, profession, socioeconomic status or their residing place, etc. For instance, a person who is with his family with all the necessities (daily needs) may not be as distressed as someone who does not have the same. Furthermore, frontline workers (such as health professionals) would be more distressed than some other professionals (such as software engineers). Essentially, for Dandekar and Ghai (2020), the impact of lockdown would also be influenced by the resources people have as witnessed in the migration of people. The plight of migrants is disturbing and has attracted the attention of the world (Ellis-Petersen and Rahman 2020). Reports of people emptying supermarkets and panic buying is indicative of how anxious people are (Nicola et al. 2020) in times of the pandemic. Students all over the world, are also experiencing distress because of the uncertainty of examinations in their schools and colleges, and with regards to availability of jobs, etc. Inspite of teachers trying their level best to teach students online, the impact of such teaching is not optimum. The primary reason being, that all students are unable to afford online platforms usage and smoothly transition to online learning which can have a huge negative effect on students' career path (Agha 2020). Cao et al. (2020) opined that anxiety issues among students during Covid-19 are related to their poor economic conditions, daily life events and hampered academic activities. In their study, Roy et al. (2020) found high levels of anxiety among Indians during the Covid-19 outbreak.

To the best of our knowledge, distress experienced (depression, anxiety and stress) by people during COVID19 has not been explored altogether so far in India. Thus, the present research is an attempt to fill this gap so that effective mental health management can be planned by practitioners and policymakers.

\section{Method}

The study was conducted from the 3rd of April 2020 to 6th of April 2020 (second week of the first national lockdown). A Google form was created and circulated on different online platforms such as Whatsapp groups and Linkedin. Online written consent was taken from all the participants before they answered the questions. The data was analysed with the help of SPSS v 21. t-test, Anova and Correlational analysis were carried out to make inferences.

\section{Sample}

A total of 403 participants completed the survey. Of the total participants, 110 were males, 291 were females and 2 preferred not to disclose their sex. The mean age of the participants was found to be 28.95 . From the sample, 139 were students, 51 were teachers, 31 were researchers, 34 were mental health professionals, 33 were health professionals (Doctors and Nurses), 35 were in a corporate job while the remaining 80 were others (e.g., homemakers, not employed, retired, businessman, etc.).

\section{Measures}

\section{Demographics}

Items related to sex, availability of essentials and professions were asked along with psychometric measures.

\section{Family Affluence Scale (Currie et al. 2008)}

The 4-item version of the scale was used to assess the socioeconomic condition of the family. The responses were coded and added as per the instructions given by the author. Two of the items were modified to suit the current research. For example, an item "during the past 12 months, how many times did you travel away on holiday with your family?" was modified to "during the past 12 months, how many times did you travel away on holiday with your family or friends?". 
Cronbach Alpha on the sample in the current study was found to be 0.6 .

\section{Response Accuracy Scale (Monaghan et al. 2020)}

The scale is a one-item measure used to assess the accuracy of the responses placed at the end of the questionnaire. Participants indicated how accurately they responded to the questionnaire on a five-point custom scale ranging from "Didn't read the questions in the survey at all" to "read all questions in the survey". Only respondents who chose "read most parts of the survey" or "read all questions in the survey" were included in the study and their responses were retained.

\section{Depression Anxiety Stress Scale (Lovibond and Lovibond 1995)}

The 21-item DASS version was used to assess depression, anxiety, and stress. There are 7 items for each subscale. The responses were collected on a 4-point rating scale ranging from 0 "didn't apply to me at all" to 3 "Applied to me very much or most of the time". Cronbach's alphas were found to be 0.85 for stress subscale, 0.75 for anxiety and 0.80 for depression subscales. The aggregated number for each subscale was multiplied by 2 and interpreted as suggested by the authors (Lovibond and Lovibond 1995). The severity ratings used to interpret are shown below:

\begin{tabular}{llll}
\hline Severity & Depression & Anxiety & Stress \\
\hline Normal & $0-9$ & $0-7$ & $0-14$ \\
Mild & $10-13$ & $8-9$ & $15-18$ \\
Moderate & $14-20$ & $10-14$ & $19-25$ \\
Severe & $21-27$ & $15-19$ & $26-33$ \\
Extremely severe & $28+$ & $20+$ & $34+$ \\
\hline
\end{tabular}

\section{Data Screening}

No missing values were found in the data. However, responses from 13 people were excluded from the analysis as they did not choose option no 4: "Read most part of the survey" or option 5: "Read all questions in the survey carefully", of the Response accuracy scale as prescribed by the authors. The excluded respondents were from different professions. Thus, the final data comprised of 390 individuals (108 males and 280 females). 2 respondents who preferred not to disclose their sex were also excluded from the gender difference analysis. For analysis (profession group difference), only students, teachers, researchers, mental health professionals, health professionals and professionals of corporate jobs were taken, while the rest were excluded from the analysis as they belonged to heterogeneous professions and their numbers were also significantly low. For example, there were 3 retirees, 4 housewives, 2 independent journalists, etc.

\section{Results}

Table 1 shows the mean differences between males and females. The mean values of stress, anxiety and depression for males were found to be 12.65, 9.91 and 10.81 respectively, with 9.26, 8.78, 9.99 standard deviations. For females, the mean values for stress, anxiety, and depression were found to be $13.44,10.57$ and 10.96 with $9.72,8.77$ and 9.76 as their respective standard deviations. The mean values of females were found to be higher than males. However, no significant difference was observed. Males and females did not differ significantly on stress $(\mathrm{t}=0.73, \mathrm{p}=0.46)$, anxiety $(\mathrm{t}=0.69, \mathrm{p}=0.50)$, and depression $(\mathrm{t}=0.12, \mathrm{p}=0.90)$. Both males and females reported mild stress, moderate anxiety, and mild depression.

Table 2 depicts differences in stress, anxiety and depression among people who had or can get daily essentials during the lockdown and people who cannot or are unsure. From the table, it can be inferred that people who did not have enough supplies were far more vulnerable than others. People who did not have enough supplies reported stress $(M=20.15)$,

Table 1 Gender differences

\begin{tabular}{llllllll}
\hline Variable & Sex & $\mathrm{N}$ & Mean & SD & Level & $\mathrm{t}$ & Sign \\
\hline Stress & Male & 108 & 12.65 & 9.26 & Mild & 0.73 & 0.46 \\
& Female & 280 & 13.44 & 9.72 & Mild & & \\
\multirow{2}{*}{ Anxiety } & Male & 108 & 9.91 & 8.78 & Moderate & 0.69 & 0.50 \\
& Female & 280 & 10.57 & 8.77 & Moderate & & \\
\multirow{3}{*}{ Depression } & Male & 108 & 10.81 & 9.99 & Mild & 0.12 & 0.90 \\
& Female & 280 & 10.96 & 9.76 & Mild & & \\
\hline
\end{tabular}


Table 2 Differences among people on the availability of daily essentials

\begin{tabular}{lllrrlrl}
\hline Variable & Availability & N & Mean & SD & Level & F & Sign \\
\hline Stress & No & 27 & 20.15 & 11.65 & Moderate & & \\
& Maybe & 33 & 14.42 & 8.66 & Mild & 8.05 & $<0.01$ \\
& Yes & 330 & 12.65 & 9.37 & Mild & & \\
Anxiety & No & 27 & 15.11 & 8.92 & Severe & & \\
& Maybe & 33 & 11.64 & 8.77 & Moderate & 5.00 & $<0.01$ \\
& Yes & 330 & 9.85 & 8.63 & Moderate & & \\
Depression & No & 27 & 16.96 & 11.52 & Moderate & & \\
& Maybe & 33 & 12.30 & 9.37 & Moderate & 6.18 & $<0.01$ \\
& Yes & 330 & 10.33 & 9.55 & Mild & & \\
\hline
\end{tabular}

anxiety $(M=15.11)$ and depression $(M=16.96)$ with 11.65 , 8.92 and 11.52 standard deviations. Further, people who were not sure about the supplies reported stress $(M=14.42)$, anxiety $(M=11.64)$, and depression $(M=12.30)$ with 8.66, 8.77 and 9.37 standard deviations. On the other hand, people who were sure and had supplies of daily essentials reported stress $(M=12.65)$, anxiety $(M=9.85)$ and depression $(\mathrm{M}=10.33)$ with $9.37,8.63$ and 9.55 standard deviations.

The respondents who did not have supplies reported a moderate level of stress, severe anxiety, and moderate depression. On the other hand, respondents who were not sure about supplies reported mild stress, moderate anxiety, and moderate depression. It was evident that respondents who had or could manage the supplies reported mild stress, moderate anxiety, and mild depression. A group difference was observed on stress $(\mathrm{F}=8.05, \mathrm{p}<0.01)$, anxiety $(\mathrm{F}=5.00$, $\mathrm{p}<0.01)$ and depression $(\mathrm{F}=6.18, \mathrm{p}<0.01)$. Further, pairwise comparison was carried out using Games Howell as the sample sizes among the groups were very different (Field 2013). A significant difference was only observed between people who had or could manage supplies and people who did not have or could not manage supplies of daily essentials on stress (Mean difference $=\mathrm{Md}=7.50, \mathrm{p}<0.001$ ), anxiety $(\mathrm{Md}=5.26, \mathrm{p}<0.02)$, and depression $(\mathrm{Md}=6.62, \mathrm{p}<0.02)$. No significant difference was observed between people who responded with "maybe" and "yes".

Table 3 shows group differences on stress, anxiety and depression. On stress, the mean values were found to be 15.57, 14.71, 11.06, 9.29, 14.61 and 8.97 for students, researchers, teachers/academicians, mental health professionals, health professions and corporate employees respectively. Their respective standard deviations were found to be $10.39,9.89,8.42,8.87,7.85$ and 8.96. A significant difference was observed $(\mathrm{F}=5.06, \mathrm{p}<0.01)$ among different kinds of professionals on stress. Students, researchers, teachers and health professionals reported mild stress, whereas
Table 3 Differences between different professions

\begin{tabular}{lllrrlll}
\hline Variable & Groups & N & Mean & SD & Level & f & Sign \\
\hline Stress & Student & 139 & 15.57 & 10.39 & Mild & & \\
& Researcher & 31 & 14.71 & 9.89 & Mild & & \\
& Teaching/academics & 51 & 11.06 & 8.42 & Mild & 5.06 & $<0.01$ \\
& Mental health professionals & 34 & 9.29 & 8.87 & Normal & & \\
& Health Professional & 33 & 14.61 & 7.85 & Mild & & \\
& Some corporate job & 35 & 8.97 & 8.96 & Normal & & \\
& Student & 139 & 12.63 & 9.46 & Moderate & & \\
& Researcher & 31 & 9.81 & 6.88 & Moderate & & \\
& Teaching/academics & 51 & 8.66 & 7.30 & Mild & & \\
& Mental health Professionals & 34 & 5.65 & 8.35 & Normal & 6.28 & $<0.01$ \\
& Health Professional & 33 & 12.55 & 6.23 & Moderate & & \\
& Some corporate job & 35 & 7.20 & 6.86 & Mild & & \\
Depression & Student & 139 & 13.97 & 10.84 & Moderate & & \\
& Researcher & 31 & 10.65 & 8.72 & Mild & & \\
& Teaching/academics & 51 & 7.84 & 7.18 & Normal & 5.88 & $<0.01$ \\
& Mental health Professionals & 34 & 6.76 & 10.04 & Normal & & \\
& Health Professional & 33 & 10.79 & 6.56 & Mild & & \\
& Some corporate job & 35 & 8.23 & 8.51 & Normal & &
\end{tabular}


mental health professionals and employees of corporates reported normal levels of stress. On anxiety, the mean values for students, researchers, teachers/academicians, mental health professionals, health professionals, and corporate employees were found to be $12.63,9.81,8.66,5.65,12.55$ and 7.20 with $9.46,6.88,7.30,8.35,6.23$ and 6.86 standard deviations respectively. A significant group difference was found on the anxiety scores $(F=6.28, p<0.01)$ among different professional groups. Students, researchers and health professionals reported moderate levels of anxiety whereas, teachers and employees reported mild levels. For mental health professionals, a normal level of anxiety was observed. As far as the mean values on depression are concerned, students, researchers, teachers/academicians, mental health professionals, health professionals, and corporate employees reported $13.97,10.65,7.84,6.76,10.79$ and 8.23 with 10.84 , $8.72,7.18,10.04,6.56$ and 8.51 standard deviations respectively. A significant difference was also observed among the groups on depression $(\mathrm{F}=5.88, \mathrm{p}<0.01)$. It was evident that teachers, mental health professionals, and employees reported normal levels of depressions, while health professionals and researchers reported mild levels. Moreover, students reported a moderate level of depression.

Further, a post hoc comparison was made using Games Howell as there was an unequal sample size among the group. On stress, a significant difference was observed only between students and teachers $(\mathrm{Md}=4.51, \mathrm{p}<0.05)$, students and mental health professionals $(\mathrm{Md}=6.27, \mathrm{p}<0.01)$, and students and employees of corporate world $(\mathrm{Md}=6.60$, $\mathrm{p}<0.01)$. No significant difference was observed among other groups on stress. Meanwhile, on anxiety, a significant difference was observed between students and teachers $(\mathrm{Md}=3.97, \mathrm{p}<0.05)$, students and mental health professionals $(\mathrm{Md}=6.99, \mathrm{p}<0.01)$, students and employees of corporate jobs $(\mathrm{Md}=5.43, \mathrm{p}<0.01)$, mental health professionals and health professionals $(\mathrm{Md}=6.90, \mathrm{p}<0.01)$, and health professionals and employees of corporate world $(\mathrm{Md}=5.35$, $\mathrm{p}<0.05$ ). No significant difference was observed among any other group. As far as depression is concerned, a significant difference was observed only between students and teachers $(\mathrm{Md}=6.13, \mathrm{p}<0.01)$, students and mental health professions $(\mathrm{Md}=7.21, \mathrm{p}<0.01)$ and students and employees of some corporate organizations $(\mathrm{Md}=5.74, \mathrm{p}<0.05)$.

Table 4 indicate the correlation between stress, anxiety, depression, and family affluence. All the correlation coefficients were found to be significant. All three aspects of psychological distress (stress, anxiety and depression) shared a high significant positive correlation with each other. The correlation coefficients between stress and anxiety and stress and depression were found to be 0.73 and 0.81 . However, between anxiety and depression, the correlation coefficient was found to be 0.70 . As far as family affluence was concerned, it shared a relatively small but significant negative
Table 4 Correlational coefficients

\begin{tabular}{|c|c|c|c|c|}
\hline Variable & Stress & Anxiety & Depression & Family affluence \\
\hline Stress & & $0.73 * *$ & $0.81 * *$ & $-0.20 * *$ \\
\hline Anxiety & & & $0.70 * *$ & $-0.18 * *$ \\
\hline Depression & & & & $-0.19 * *$ \\
\hline
\end{tabular}

**Correlation coefficient was found to be significant at 0.01 level

correlation with stress $(\mathrm{r}=-0.20)$, anxiety $(\mathrm{r}=-0.18)$, and depression $(r=-0.19)$.

\section{Discussion}

The main aim of the present research was to explore the levels of psychological distress (stress, anxiety, and depression) among different sections of the Indian population. The data was collected from different professionals including students for this study. As far as gender differences on stress, anxiety, and depression were concerned, both males and females seemed to suffer equally. The levels of stress and depression were found to be mild, whereas the levels of anxiety were moderate among males and females. This could be because the current lockdown and fear of getting infected with Covid-19 are so pervasive, that similar experiences of distress are evident irrespective of gender.

Clearly, people who did not have or were unable to get enough supplies of daily essentials were most affected by the lockdown. Even though levels of stress and depression were found to be moderate, severe anxiety issues which could be attributed to the current situation were evident. What is noteworthy however, is that people who were not sure about supplies and those who had enough supplies seem to be affected less. Perhaps, people who were not sure about their supplies were either thinking of shared consequences or relying on their sources for future use.

Also, the findings of the current study shed light on how students and health professionals have suffered during the pandemic, which is in line with other studies (Sahu 2020; Cao et al. 2020; Law 2020). Essentially, students, researchers, teachers, and health professionals reported mild levels of stress, whereas mental health professionals and employees in different corporate jobs were found to be in the normal range of stress. These finding could be attributed to the closure of universities and colleges that offer limited technological support and knowledge resulting in uncertainty about the future of students, teachers, and researchers. The current pandemic places demands on students and teachers alike to adapt to online teaching albeit with limited resources, thus resulting in above normal stress levels. Furthermore, closure of hospitals for general OPDs may have been stressful for the medical staff who may fear getting infected. What 
needs to be noted though, is that mental health professions and employees of corporate organizations seem to have remained untouched by the pandemic situation. The probable reason could be that mental health professionals are resilient enough to deal with the situation and employees of corporates can easily work from home on their laptops.

As far as anxiety is concerned, students, researchers, and health professionals reported a moderate level of anxiety, whereas, teachers and corporate employees reported mild levels of stress. These findings could be because students and researchers (mostly Ph.D. scholars in social sciences faculty) engage and interact with each other frequently and physically in a social setting. During lockdown, with the closure of universities and colleges, such physical and social interaction has been restricted resulting in stress. For learning, students and researchers have to utilise online platforms that they may not be used to or competent with. In addition, online learning may be disruptive due to technological issues and thereby, jeopardizing their future careers. Conversely, for health care professionals, many are not working in the manner that they did earlier (because of lockdown and government restrictions on OPDs), and those who are working are fatigued and stressed since they have to work in extremely challenging situations and for long hours. Notably, many frontline doctors and health care professionals have been infected with COVID-19 (Jeelani and Gupta 2020).

Further, in the current study, it is evident that depression was not reported for teachers and employees working in the corporate sector. Perhaps, for these professionals their security and financial stability helps them cognitively counter the adverse effects of the lockdown. On the contrary, for researchers and health professionals, depression was reportedly mild, indicative of the mental health ramifications due to the rapid spread of the coronavirus (Roy et al. 2020). On the other hand, students were found to be moderately depressed which can probably be attributed to changes in their day-to-day life and in their teaching-learning activities.

However, a positive finding from this research was that mental health professionals reported normal levels of stress, anxiety, and depression during this pandemic. Evidence suggests that people in general are experiencing distress (Bansal 2020) and that they are seeking the services of mental health professionals. Essentially, Indian mental health professionals are resilient enough to help people in distress. Clearly, the development of a medical protocol for affected sections of society (students and health professionals) is much needed, so as to enable them to remain resilient even during the worst conditions. Despite the low correlation coefficient between family affluence and psychological distress (depression, anxiety and stress), the results of the correlational analysis complemented the findings of distress among people who did not have enough supplies. The low correlation signifies that despression, anxiety, and stress does not only depend on the financial resources of the family but is also related to the socio-economic status of a family. In fact, it can be alluded that people with good or high socio-economic status may get enough supplies, thus, making them less prone to psychological distress.

\section{Conclusion}

The present study is a frontrunner in exploring levels of anxiety, stress, and depression in the Indian population. The research findings indicate that students and health professionals need special attention because of their higher psychological distress. It is imperative that governments, NGOs and other agencies that are instrumental in distributing and delivering (daily essentials) focus more on people who do not have enough supplies. Lastly, policymakers also need to care for students and health professionals as the main stakeholders in the society.

\section{Limitations}

Although the research has made significant contributions and can be used by the government and other agencies to tackle the adverse psychological effects during Covid-19 and lockdown, it has some limitations. Firstly, the size of the sample in some groups was quite small. Secondly, the researchers utilised online Google forms for data collection that hindered the participation of a larger section of the population such as those who do not have internet, especially the underprivileged.

Acknowledgements We would like to thank Ms. Nanaki J. Chadha for her valuable comments on the manuscript.

Funding No funding was sought for the current research.

\section{Compliance with Ethical Standards}

Conflict of interest The authors declare no conflict of interest.

\section{References}

Agha, E. (2020, April 14). Learning rebooted: Online education during Covid-19 lockdown puts spotlight on India's digital divide. Retrieved from https://www.news18.com/news/india/learningrebooted-online-education-during-covid-19-lockdown-puts-spotl ight-on-indias-digital-divide-2563265.html.

Bansal, V. (2020, April 17). Online therapy platforms offering anonymity are helping India's Covid-19 related mental health crisis. Retrieved from https://entrackr.com/2020/03/online-therapy-covid -19-mental-health-crisis/.

Cao, W., Fang, Z., Hou, G., Han, M., Xu, X., Dong, J., et al. (2020). The psychological impact of the COVID-19 epidemic on college 
students in China. Psychiatry Research. https://doi.org/10.1016/j. psychres.2020.112934.

Chetterje, P. (2020). Gaps in India's preparedness for COVID-19 control. The Lancet Infectious Diseases, 20(5), 544. https://doi. org/10.1016/s1473-3099(20)30300-5.

Cheng, V., Wong, S., Chuang, V., So, S., Chen, J., Sridhar, S., et al. (2020). The role of community-wide wearing of face mask for control of coronavirus disease 2019 (COVID-19) epidemic due to SARS-CoV-2. Journal of Infection. https://doi.org/10.1016/j. jinf.2020.04.024.

Currie, C., Molcho, M., Boyce, W., Holstein, B., Torsheim, T., \& Richter, M. (2008). Researching health inequalities in adolescents: The development of the Health Behaviour in SchoolAged Children (HBSC) Family Affluence Scale. Social Science \& Medicine, 66(6), 1429-1436. https://doi.org/10.1016/j.socsc imed.2007.11.024.

Dandekar, A., \& Ghai, R. (2020). Migration and reverse migration in the age of COVID-19. Economic \& Political Weekly, 55(19), $28-31$.

Ellis-Petersen, H., \& Rahman, S. (2020, April 14). 'I just want to go home': The desperate millions hit by Modi's brutal lockdown. Retrieved from https://www.theguardian.com/world/2020/apr/04/ i-just-want-to-go-home-the-desperate-millions-hit-by-modis-bruta 1-lockdown.

Field, A. (2013). Discovering statistics using IBM SPSS statistics (4th ed.). London: SAGE.

Goyal, K., Chauhan, P., Chhikara, K., Gupta, P., \& Singh, M. (2020). Fear of COVID 2019: First suicidal case in India! Asian Journal of Psychiatry, 49, 101989. https://doi.org/10.1016/j.ajp.2020.10198 9.

Hall, R., Hall, R., \& Chapman, M. (2008). The 1995 Kikwit Ebola outbreak: Lessons hospitals and physicians can apply to future viral epidemics. General Hospital Psychiatry, 30(5), 446-452. https://doi.org/10.1016/j.genhosppsych.2008.05.003.

Hawryluck, L., Gold, W., Robinson, S., Pogorski, S., Galea, S., \& Styra, R. (2004). SARS control and psychological effects of quarantine, Toronto, Canada. Emerging Infectious Diseases, 10(7), 1206-1212. https://doi.org/10.3201/eid1007.030703.

Holland, K. (2018, May 24). Anxiety: Causes, symptoms, treatment, and more. Retrieved 24 from https://www.healthline.com/healt h/anxiety.

Jeelani, G., \& Gupta, I. (2020, April 17). Covid-19: Centre steps in as doctors get infected. Retrieved from https://www.indiatoday .in/mail-today/story/covid-19-centre-steps-doctors-get-infected1662377-2020-04-02.

Kaplan, J., Frias, L., \& McFall-Johnsen, M. (2020, April 13). A third of the global population is on coronavirus lockdown - Here's our constantly updated list of countries and restrictions. Retrieved from https://www.businessinsider.com/countries-on-lockdowncoronavirus-italy-2020-3? IR $=\mathrm{T}$.

Kumar, A., \& Nayar, K. R. (2020). COVID 19 and its mental health consequences. Journal of Mental Health. https://doi. org/10.1080/09638237.2020.1757052.

Law, T. (2020, April 17). Medical workers fighting COVID-19 are facing a mental health crisis. Retrieved from https://time.com/58174 35/covid-19-mental-health-coronavirus/.

Leung, G., Lam, T., Ho, L., Ho, S., Chan, B., Wong, I., et al. (2003). The impact of community psychological responses on outbreak control for severe acute respiratory syndrome in Hong Kong. Journal of Epidemiology \& Community Health, 57(11), 857-863. https://doi.org/10.1136/jech.57.11.857.

Lovibond, S. H., \& Lovibond, P. F. (1995). Manual for the Depression Anxiety Stress Scales (2nd ed.). Sydney: DASS Publications.

Mamun, M., \& Griffiths, M. (2020). First COVID-19 suicide case in Bangladesh due to fear of COVID-19 and xenophobia: Possible suicide prevention strategies. Asian Journal Of Psychiatry, 51, 102073. https://doi.org/10.1016/j.ajp.2020.102073.
McAlonan, G., Lee, A., Cheung, V., Cheung, C., Tsang, K., Sham, P., et al. (2007). Immediate and sustained psychological impact of an emerging infectious disease outbreak on health care workers. The Canadian Journal of Psychiatry, 52(4), 241-247. https://doi. org/10.1177/070674370705200406.

Monaghan, C., Bizumic, B., Williams, T., \& Sellbom, M. (2020). Twodimensional Machiavellianism: Conceptualization, theory, and measurement of the views and tactics dimensions. Psychological Assessment, 32(3), 277-293. https://doi.org/10.1037/pas0000784.

Nicola, M., Alsafi, Z., Sohrabi, C., Kerwan, A., Al-Jabir, A., Iosifidis, C., et al. (2020). The socio-economic implications of the Coronavirus and COVID-19 pandemic: A review. International Journal of Surgery. https://doi.org/10.1016/j.ijsu.2020.04.018.

Qiu, J., Shen, B., Zhao, M., Wang, Z., Xie, B., \& Xu, Y. (2020). A nationwide survey of psychological distress among Chinese people in the COVID-19 epidemic: Implications and policy recommendations. General Psychiatry, 33(2), e100213. https://doi. org/10.1136/gpsych-2020-100213.

Roy, D., Tripathy, S., Kar, S., Sharma, N., Verma, S., \& Kaushal, V. (2020). Study of knowledge, attitude, anxiety \& perceived mental healthcare need in Indian population during COVID-19 pandemic. Asian Journal of Psychiatry, 51, 102083. https://doi. org/10.1016/j.ajp.2020.102083.

Sahu, D., Agrawal, T., Rathod, V., \& Bagaria, V. (2020). Impact of COVID 19 lockdown on orthopaedic surgeons in India: A survey. Journal of Clinical Orthopaedics and Trauma. https://doi. org/10.1016/j.jcot.2020.05.007.

Sahu, P. (2020). Closure of universities due to Coronavirus Disease 2019 (COVID-19): Impact on education and mental health of students and academic staff. Cureus. https://doi.org/10.7759/cureu s.7541.

Sanders, J., Monogue, M., Jodlowski, T., \& Cutrell, J. (2020). Pharmacologic treatments for Coronavirus Disease 2019 (COVID-19). JAMA. https://doi.org/10.1001/jama.2020.6019.

Selye, H. (1956). The stress of life. New York: McGraw-Hill.

Usher, K., Durkin, J., \& Bhullar, N. (2020). The COVID-19 pandemic and mental health impacts. International Journal of Mental Health Nursing. https://doi.org/10.1111/inm.12726.

Van Bortel, T., Basnayake, A., Wurie, F., Jambai, M., Koroma, A., Muana, A., et al. (2016). Psychosocial effects of an Ebola outbreak at individual, community and international levels. Bulletin of the World Health Organization, 94(3), 210-214. https://doi. org/10.2471/blt.15.158543.

Wang, C., Pan, R., Wan, X., Tan, Y., Xu, L., Ho, C., et al. (2020). Immediate psychological responses and associated factors during the initial stage of the 2019 Coronavirus Disease (COVID-19) epidemic among the general population in China. International Journal of Environmental Research and Public Health, 17(5), 1729. https://doi.org/10.3390/ijerph17051729.

WHO. (2020). Mental health and psychosocial considerations during the COVID-19 outbreak [Ebook]. Retrieved from https://www. who.int/docs/default-source/coronaviruse/mental-health-consi derations.pdf.

Worldometers. (2020, April 13). Retrieved from https://www.world ometers.info/coronavirus/.

Xiang, Y., Yang, Y., Li, W., Zhang, L., Zhang, Q., Cheung, T., et al. (2020). Timely mental health care for the 2019 novel coronavirus outbreak is urgently needed. The Lancet Psychiatry, 7(3), 228229. https://doi.org/10.1016/s2215-0366(20)30046-8.

Publisher's Note Springer Nature remains neutral with regard to jurisdictional claims in published maps and institutional affiliations. 